\title{
EFFICACY AND SAFETY OF TREATMENT OF HEPATITIS C IN PATIENTS WITH INFLAMMATORY BOWEL DISEASE
}

\author{
Alina M. Allen ${ }^{1}$, W. Ray Kim ${ }^{1}$, Joseph Larson ${ }^{2}$, and Edward V. Loftus Jr. ${ }^{1}$ \\ ${ }^{1}$ Division of Gastroenterology and Hepatology, Mayo Clinic, Rochester, Minnesota, U.S.A \\ ${ }^{2}$ Division of Biostatistics and Informatics, Mayo Clinic, Rochester, Minnesota, U.S.A
}

\section{Abstract}

Background \& Aims-There is uncertainty about the efficacy and safety of treatment for hepatitis $\mathrm{C}$ virus (HCV) infection in patients with inflammatory bowel disease (IBD). IBD can become exacerbated during treatment with interferon (IFN) and serious adverse events, such as pancytopenia or hepatotoxicity, can be compounded by drug interactions. We investigated the risk of exacerbation of IBD during HCV therapy and the rate of adverse effects of concomitant therapy for HCV and IBD. We also evaluated the efficacy of HCV treatment in the IBD population.

\begin{abstract}
Methods-We conducted a retrospective review of all patients who underwent IFN-based treatment for HCV at the Mayo Clinic in Rochester, Minnesota from 2001 through 2012. Exacerbation of IBD was evaluated by clinical, endoscopic, and histologic parameters during antiviral therapy and the ensuing 12 months. Hematologic toxicity was assessed by levels of all 3 cell lineages at baseline and during therapy. Efficacy of antiviral treatment was assessed by serum levels of HCV RNA until 24 weeks after completion of therapy. We also conducted a detailed Medline database search and reviewed the literature on this topic.
\end{abstract}

Results-We identified 15 subjects with concomitant IBD ( 8 with ulcerative colitis and 7 with Crohn's disease). Only 1 patient experienced an exacerbation of the disease during therapy; symptoms were controlled with mesalamine enemas. Another patient developed a flare shortly after completing antiviral therapy; symptoms returned spontaneously to baseline 2 weeks later. All subjects experienced an anticipated degree of pancytopenia while on IFN-based therapy. The rate of sustained virologic response was $67 \%$. A concise review of available literature regarding the safety and efficacy of HCV treatment in IBD patients is also presented; although limited, the published data appears to support the safety of treatment with IFN in patients whose IBD is under control.

\footnotetext{
(C) 2013 The American Gastroenterological Association. Published by Elsevier Inc. All rights reserved.

Correspondence: W. Ray Kim, 200 First Street SW, Rochester, MN, kim.woong@mayo.edu, Phone: 507-284-3917, Fax: 507-284-0538.

Disclosures: The authors disclose no conflicts of interest.

Author contributions:

Alina Allen: study concept and design, acquisition of data, analysis and interpretation of data, drafting of the manuscript Joseph Larson: acquisition of data, statistical analysis

Edward V. Loftus: study concept and design, critical revision of the manuscript for important intellectual content W. Ray Kim: study concept and design, critical revision of the manuscript for important intellectual content, study supervision

Publisher's Disclaimer: This is a PDF file of an unedited manuscript that has been accepted for publication. As a service to our customers we are providing this early version of the manuscript. The manuscript will undergo copyediting, typesetting, and review of the resulting proof before it is published in its final citable form. Please note that during the production process errors may be discovered which could affect the content, and all legal disclaimers that apply to the journal pertain.
} 
Conclusions-In conjunction with data from the literature, our findings indicate that the efficacy and safety of HCV therapy with IFN and ribavirin for patients with IBD are comparable to those of subjects without IBD.

\author{
Keywords \\ UC; CD; SVR; inflammation
}

\title{
INTRODUCTION
}

Patients with concomitant inflammatory bowel disease (IBD) and hepatitis $\mathrm{C}$ virus (HCV) infection represent a complex subset of patients. $\mathrm{HCV}$ is a common infection worldwide, with a high and increasing rate of progression to cirrhosis and hepatocellular carcinoma (HCC).

The concern with IFN therapy is its immune-modulatory action, which may possibly worsen the clinical course of IBD. On the other hand, the immunosuppressive therapy for IBD can potentially lead to a more rapid progression of fibrosis in $\mathrm{HCV}$-infected patients ${ }^{1}$. Another aspect underlying the reluctance to treat $\mathrm{HCV}$ is the potential for serious adverse events, such as pancytopenia or hepatotoxicity, resulting from the interaction between $\mathrm{HCV}$ - and IBD- specific agents ${ }^{2}$.

Thus, the management of patients with concomitant IBD and HCV infection remains a clinical challenge. Evidence based recommendation about the efficacy and safety of HCV treatment in patients with IBD is difficult to make, in part because of the paucity of data.

The aims of this study are: (i) to determine the risk of IBD exacerbation during HCV therapy and the rate of adverse effects of concomitant therapy for HCV and IBD; and (ii) to evaluate the efficacy of HCV treatment in the IBD population. In addition, we review the available literature on this topic.

\section{PATIENTS AND METHODS}

We conducted a retrospective review of all patients who underwent IFN-based treatment for HCV at Mayo Clinic, Rochester, Minnesota, between 2001 and 2012. The study was approved by the Institutional Review Board of Mayo Clinic.

Exacerbation of inflammatory bowel disease was evaluated by clinical, endoscopic and histologic parameters during antiviral therapy and the ensuing 12 months. Clinical assessment was extracted from medical records documented during the aforementioned period by any medical provider. Management of viral hepatitis in our practice involved frequent blood testing and scheduled telephone conversations with viral hepatitis nurses, as well as clinic visits with the hepatologist at baseline, weeks 4, 12, 24 and 48 of therapy, and week 24 from completion. This close follow-up ensured that no IBD flares were missed. All available endoscopic evaluations and histology reports were reviewed. IBD flares were defined as an increase in baseline stool frequency, presence of blood in stool, abdominal discomfort, correlated with increased disease activity per endoscopic and histologic assessment.

For the secondary end-point of safety profile of concomitant antiviral and IBD treatment, hematologic toxicity was assessed by levels of all 3 cell lineages at baseline and during therapy. Results were reported in median values and median of changes in values. 
Efficacy of antiviral treatment was assessed by measurement of serum HCV RNA level at baseline and up to 24 weeks after discontinuation of therapy. Testing was performed by COBAS Ampli/Prep HCV test (Roche Molecular Systems Inc., quantification range 43 IU/ $\mathrm{mL}$ to $69,000,000 \mathrm{IU} / \mathrm{mL}$ ). Sustained virologic response (SVR) was defined as undetectable HCV RNA levels at 24 weeks after completion of antiviral therapy.

\section{RESULTS}

\section{Exacerbation of inflammatory bowel disease during HCV therapy}

Of 1017 patients treated for HCV during the study period, 15 had concomitant IBD [8 with ulcerative colitis (UC) and 7 with Crohn's disease (CD)]. The median age at initiation of antiviral therapy was 53 years (range, 30-68). Two patients received antiviral therapy twice; therefore, 17 treatment courses were observed. The bowel disease characteristics of the study population are summarized in Table 1, whereas the liver disease characteristics are summarized in Table 2 .

All subjects had inactive bowel disease prior to IFN initiation, except 1 patient with CD who had not been on maintenance treatment. He was started on budesonide at the time of HCV therapy and maintained clinical remission throughout the study period. Eight patients were on IBD-specific therapy prior to HCV treatment (5 on mesalamine, 2 on mesalamine plus azathioprine, and one on budesonide).

Only 1 patient experienced increased stool frequency (from 4-6 to 6-8 stools/day) and abdominal cramping within 1 month of IFN initiation (patient 7, Table 3). The patient had a diagnosis of left-sided UC and was on maintenance therapy with oral mesalamine and intermittent mesalamine enemas. She carried a concomitant diagnosis of irritable bowel syndrome (IBS), based on similar prior intermittent complaints of increased stool frequency and abdominal cramping, in the context of endoscopic and histologic evidence of inactive or mildly active colitis. Her symptoms were controlled with the addition of mesalamine enemas, but persisted after antiviral therapy was discontinued at 12 weeks, given her nonresponder status. Colonoscopy performed 9 months later showed features of chronic inactive left-sided colitis, similar to the endoscopic features noted immediately prior to antiviral therapy. Random colon biopsies revealed moderately active UC (previously with minimal activity).

Another patient (no. 15) with mildly active CD, on budesonide treatment, tolerated 6 months of pegylated IFN (PegIFN) and ribavirin, but developed worse non-bloody diarrhea and abdominal pain within 2 weeks from ending antiviral treatment. Budesonide was continued and symptoms returned to baseline spontaneously 2-3 weeks later.

\section{Safety profile of concomitant therapy for IBD and HCV}

All patients experienced an anticipated degree of pancytopenia while on IFN-based therapy. The mean decline in all three cell lines is summarized in Table 4. No treatment was stopped due to pancytopenia. Five patients required adjustment of therapy (lower azathioprine dose in 1 patient for leukopenia, lower ribavirin dose in 2 patients for anemia, and lower PegIFN dose in 2 patients for leukopenia and anemia, respectively). Erythropoietin was used in 2 patients.

Hepatotoxicity was not observed in subjects under concomitant treatment with azathioprine. 


\section{Efficacy of HCV treatment in IBD population}

Antiviral treatment consisted mainly of the combination of PegIFN- $a$ and ribavirin in 12 patients. One patient was treated with PegIFN-a monotherapy due to baseline anemia, and two patients received telaprevir-containing triple therapy. Treatment was completed and well tolerated in all but 1 subject (6.6\%), who discontinued therapy at week 20 due to abdominal pain, without diarrhea.

Individual treatment responses are summarized in Table 3. Overall SVR rate was 67\% (50\% for genotype 1, 100\% for genotype 2 and $100 \%$ for genotype 3 ).

\section{LITERATURE REVIEW}

\section{Risk of IBD exacerbation with interferon}

The effects of IFN on IBD activity, perhaps the major concern underlying the reluctance to treat HCV in these patients, have been mixed. Currently still the mainstay of HCV therapy, IFN- $a$ is a pro-inflammatory cytokine which stimulates a Th1-type immune response, similar to the immunologic milieu of $\mathrm{CD}^{3}$. On the other hand, IFN-a has anti-inflammatory properties via regulation and down-modulation of Th2 cytokines, which are upregulated in $\mathrm{UC}^{4}$. Therefore, both theoretical assumptions of IBD exacerbation or remission are plausible, but none have been confirmed in the literature. These studies, however, are limited by a small number of patients.

Randomized controlled trials-Tilg et al. conducted a randomized placebo-controlled trial to evaluate the efficacy of PegIFN-a as treatment agent for UC ${ }^{5}$. The treatment did not appear to be effective, but, more importantly, there were no cases of UC exacerbation in the treatment groups. Although the PegIFN-a doses used in this trial are lower than the ones used to treat $\mathrm{HCV}$, this study supports the safety of IFN even in active UC. Favorable treatment outcomes were also noted in a randomized trial of IFNa-2a versus prednisolone enemas in 32 patients with left sided colitis ${ }^{6}$.

Prospective studies-A case-control study followed 21 patients with IBD and 65 controls during 12 months of IFN monotherapy for HCV. There was no worsening in IBD activity or difference in frequency or severity of side effects between cases and controls ${ }^{7}$. A prospective, open-label study of 28 patients with ulcerative colitis treated with IFNa-2a for 6 months led to complete remission in $82 \%$ of cases $^{8}$

Retrospective studies-Cottone et al evaluated 14 patients with IBD who underwent IFN-a monotherapy for HCV for at least 6 months. Only one patient, with initially inactive disease, had a mild flare during treatment ${ }^{9}$. Scherzer and colleagues ${ }^{10}$ assessed 11 patients with $\mathrm{CD}$ who were treated for hepatitis $\mathrm{C}$. Therapy was overall well tolerated, with a mild increase in stool frequency in 6 patients. They temporarily required escalation of CDspecific therapy with corticosteroids and/or mesalamine. Favorable outcomes of two patients are also described in another study ${ }^{11}$.

Case reports-Most of the controversy regarding the negative outcomes of IFN-a on IBD comes from case reports. A review of the literature revealed 24 unfavorable case reports. Of these, 21 were new-onset IBD ( $15 \mathrm{UC}^{12-24}, 5 \mathrm{CD}^{21,25,26}$ and 1 "IBD-like"27) and 3 were exacerbations ( $2 \mathrm{UC}^{28,29}$ and $1 \mathrm{CD}^{30}$ ), either during or after discontinuation of IFN. It is important to note that most of the IBD cases were mild and responded to discontinuation of IFN or administration of mesalamine. Furthermore, most patients who had negative outcome were not on maintenance therapy for IBD prior to HCV treatment, suggesting that perhaps assuring remission of IBD prior to consideration of antiviral therapy may avoid flares. 
On the other hand, 6 case reports with a favorable IBD outcome while on treatment with IFN- $a$ with or without ribavirin were found on literature review 22,31-35. All cases were on IBD maintenance therapy during antiviral treatment and no flares were documented.

\section{Safety profile of concomitant therapy for IBD and HCV}

Azathioprine (AZA) and 6-mercaptopurine (6-MP) have known dose-related toxicities, such as pancytopenia (related to 6-thioguanine nucleotide (6-TGN) levels) and hepatotoxicity (due to methylated derivatives) ${ }^{36}$. Ribavirin efficiently blocks inosine monophosphate dehydrogenase (IMPDH) ${ }^{37}$, therefore shifting the metabolism towards methylated products, and away from 6-TGN (Figure 1) ${ }^{2}$. Two concerns arise from this interaction: hepatotoxicity due to an accumulation of 6-MMPN, and potential IBD flares, due to lower 6-TGN levels.

\section{Efficacy of HCV treatment in IBD population}

There is consensus that the efficacy of HCV treatment in IBD patients is comparable to that in the non-IBD population. In a case-control study ${ }^{7}$ assessing the efficacy of non-PegIFN monotherapy for HCV in patients with IBD versus controls, similar SVR rates were reported. The efficacy of HCV therapy with a combination of PegIFN-a and ribavirin was assessed in a prospective study ${ }^{10}$ of $11 \mathrm{CD}$ patients, of whom $46 \%$ achieved SVR, $27 \%$ relapsed and $27 \%$ were non-responders.

\section{Effects of IBD therapy on HCV infection}

Corticosteroids-There are no studies directed at the effects of corticosteroids used for IBD flares on the course of $\mathrm{HCV}$, except for case reports ${ }^{38,39}$. The liver transplantation literature suggests a significant increase of $\mathrm{HCV}$ viremia in patients receiving corticosteroid boluses (much higher doses than typically used for IBD exacerbations) for acute allograft rejection after liver transplantation for $\mathrm{HCV}^{40}$. The effects of corticosteroid use on progression of HCV-related liver fibrosis are controversial ${ }^{1,41}$. Based on this scarce data, we believe it is reasonable to conclude that steroids may temporarily allow uninhibited HCV replication, either related to high doses or to rapid dose alterations. If steroid use is inevitable for control of IBD exacerbations, the lowest beneficial dose and slow tapering is advisable.

Thiopurines-To date, no studies have evaluated the safety of immunomodulators in HCV among IBD patients. AZA has shown antiviral activity on $\mathrm{HCV}$ in vitro ${ }^{42}$. In the posttransplant setting, some have suggested that AZA may be beneficial in HCV recurrence ${ }^{43}$. There is no evidence that the immunosuppressive effects of AZA adversely affect the course of HCV. All in all, we believe that thiopurines in IBD patients with $\mathrm{HCV}$ are probably safe and possibly beneficial.

Biologics-Studies have shown that TNF levels correlate with hepatitis activity ${ }^{44}$, suggesting that anti-TNF agents may play a beneficial role on HCV course. In a randomized placebo-controlled trial in $\mathrm{HCV}$ patients ${ }^{45}$, adding etanercept to IFN and ribavirin for 24 weeks resulted in a greater rate of viral clearance when compared to a standard regimen. At present, biologic agents appear safe ${ }^{11,46-47}$ in $\mathrm{HCV}$-infected patients; however, long-term studies are needed.

\section{DISCUSSION}

In this study we present our experience with the treatment of hepatitis $\mathrm{C}$ in IBD patients, with emphasis on the risk of exacerbation of IBD during therapy with IFN, the safety profile of medications, and the efficacy of HCV therapy in this patient population. In addition, we review all available literature on this controversial topic. 
In this retrospective cohort, therapy was overall well tolerated, with only one patient experiencing a mild increase in baseline stool frequency, without gross endoscopic changes, but with slightly increased inflammation per biopsies. It is unclear if the subtle histologic changes were due to IFN or natural progression of her disease, or if her symptoms were related to IBD or IBS. The fact that the patient continued to complain of similar intermittent, self-remitting flares during the following 5 years, with unchanged endoscopic features and stable minimal-moderate activity, points away from IFN as a causal factor. The second patient experienced a temporary flare after completion of $\mathrm{HCV}$ treatment, which resolved spontaneously.

Overall our study supports the evidence that IFN-based therapy for HCV is safe and well tolerated in IBD patients, as long as the disease is under control (remission or minimal activity) prior to initiation of antivirals. Although rare, flares are minimal and easily handled with standard therapy. The presence of IBD, while taken into careful consideration, should not lead to automatic deferral of HCV therapy when indicated.

In regards to medication toxicity, antiviral therapy with IFN and ribavirin is safe and should not be withheld only on the premises of concomitant use of immunomodulators. Cytopenias were noted at rates comparable or slightly lower than the ones published in the literature ${ }^{48}$ (Supplementary Table 1). In our study, concomitant treatment with IFN, ribavirin and AZA occurred in 2 patients, and neither experienced IBD flares, hepatotoxicity, or required transfusion or cell stimulating factors. Frequent monitoring for possible myelotoxicity and hepatotoxicity remains imperative, especially in subjects with high TPMT activity, in whom methylated products are expected to increase.

Our single center experience confirms that treatment of hepatitis $\mathrm{C}$ in IBD patients is as effective as in general population. The overall SVR rate was $67 \%$. There were 2 patients who completed telaprevir-based triple therapy, both of whom achieved SVR.

The available literature, including our study, has limitations. Most of the reports include patients with, at most, moderately active IBD, as reflected by the IBD-specific agents used. Approximately half of the patients in our study were on maintenance therapy, which included mesalamine and AZA. The risk of IBD exacerbation in harder-to-treat patients, such as those on combination therapy with biologics and immunomodulators, remains unknown. In those situations, HCV treatment should be individualized, and the risks of liver disease progression if left untreated should be carefully weighed against the potential risks of IBD flares. In light of emerging direct-acting anti-HCV agents that may obviate the need for IFN, these patients without advanced fibrosis or other indication for immediate treatment may be best counseled to wait. The number of patients included in these studies and reports, including ours, is relatively small. Although we present only 15 patients, our study provides an additional center experience to the scarce available literature. We report the first 2 cases of telaprevir-containing therapy, which appears safe in IBD patients.

In conclusion, based on our experience, in patients whose IBD activity is under control with or without therapy, HCV treatment with IFN and ribavirin is safe and effective. Thorough evaluation and management of IBD activity prior to initiation of antivirals and continuation of maintenance therapy is recommended. Flares of IBD are mild and easily handled with first-line therapy. Corticosteroids can be cautiously used during exacerbations, but at a minimum effective dose and tapered slowly. Based on the available literature, IBD treatment with immunomodulators and biologics do not seem to alter the course of HCV. AZA and 6MP can be used concomitantly with IFN and ribavirin, although medication interactions can, in theory, lead to worse hepatotoxicity, myelotoxicity and IBD exacerbation due to relative 
resistance to thiopurines. Although TPMT phenotype may help predict toxicities, frequent screening for myelosuppression and hepatotoxicity remains the safest practice.

\section{Supplementary Material}

Refer to Web version on PubMed Central for supplementary material.

\section{References}

1. Berenguer M, Ferrell L, Watson J, et al. HCV-related fibrosis progression following liver transplantation: increase in recent years. Journal of hepatology. 2000; 32:673-84. [PubMed: 10782918]

2. Peyrin-Biroulet L, Cadranel JF, Nousbaum JB, et al. Interaction of ribavirin with azathioprine metabolism potentially induces myelosuppression. Alimentary pharmacology \& therapeutics. 2008; 28:984-93. [PubMed: 18657132]

3. Tilg H. New insights into the mechanisms of interferon alfa: an immunoregulatory and antiinflammatory cytokine. Gastroenterology. 1997; 112:1017-21. [PubMed: 9041265]

4. Fuss IJ, Heller F, Boirivant M, et al. Nonclassical CD1d-restricted NK T cells that produce IL-13 characterize an atypical Th2 response in ulcerative colitis. The Journal of clinical investigation. 2004; 113:1490-7. [PubMed: 15146247]

5. Tilg H, Vogelsang H, Ludwiczek O, et al. A randomised placebo controlled trial of pegylated interferon alpha in active ulcerative colitis. Gut. 2003; 52:1728-33. [PubMed: 14633951]

6. Madsen S, Schlichting P, Davidsen B, et al. An open-labeled, randomized study comparing systemic interferon-alpha-2A and prednisolone enemas in the treatment of left-sided ulcerative colitis. American Journal of Gastroenterology. 2001; 96:1807-15. [PubMed: 11419834]

7. Bargiggia S, Thorburn D, Anderloni A, et al. Is interferon-alpha therapy safe and effective for patients with chronic hepatitis $\mathrm{C}$ and inflammatory bowel disease? A case-control study Alimentary pharmacology \& therapeutics. 2005; 22:209-15.

8. Sumer N, Palabiyikoglu M. Induction of remission by interferon-alpha in patients with chronic active ulcerative colitis. European Journal of Gastroenterology and Hepatology. 1995; 7:597-602. [PubMed: 8590152]

9. Cottone M, Magliocco A, Trallori G, et al. Clinical course of inflammatory bowel disease during treatment with interferon for associated chronic active hepatitis. The Italian journal of gastroenterology. 1995; 27:3-4. [PubMed: 7795286]

10. Scherzer TM, Staufer K, Novacek G, et al. Efficacy and safety of antiviral therapy in patients with Crohn's disease and chronic hepatitis C. Alimentary pharmacology \& therapeutics. 2008; 28:7428. [PubMed: 19145730]

11. Katsanos K, Tsianos V, Zois C, et al. Inflammatory bowel disease and hepatitis B and C in Western Balkans: a referral centre study and review of the literature. Journal of Crohn's and Colitis. 2010; 4:450-65.

12. Miike T, Tahara Y, Yamaguchi Y, et al. A case study: interferon-beta-induced remission of ulcerative colitis in a patient with type $\mathrm{C}$ chronic hepatitis. The Japanese journal of gastroenterology. 2008; 105:1362-6.

13. Sprenger R, Sagmeister M, Offner F. Acute ulcerative colitis during successful interferon/ribavirin treatment for chronic hepatitis. Gut. 2005; 54:438-9. [PubMed: 15710996]

14. Villa F, Rumi MG, Signorelli C, et al. Onset of inflammatory bowel diseases during combined alpha-interferon and ribavirin therapy for chronic hepatitis $\mathrm{C}$ : report of two cases. European journal of gastroenterology \& hepatology. 2005; 17:1243-5. [PubMed: 16215439]

15. Awakawa T, Hirohashi S, Hasegawa K, et al. A case of acute phase ulcerative colitis like colitis developed by the interferon-beta therapy for chronic hepatitis $\mathrm{C}$. The Japanese journal of gastroenterology. 2003; 100:680-4.

16. Niki T, Nishida K, Honsako Y, et al. A case of ulcerative colitis along with characteristic features on computed tomography (CT), developed by the treatment with interferon for chronic hepatitis C. The Japanese journal of gastro-enterology. 2001; 98:399-404. 
17. Mavrogiannis C, Papanikolaou IS, Elefsiniotis IS, et al. Ulcerative colitis associated with interferon treatment for chronic hepatitis C. Journal of hepatology. 2001; 34:964-5. [PubMed: 11451187]

18. Usami, T. Rinshohinyokika. 1999. Interferon induced ulcerative colitis-like acute colitis.

19. Honda, K. Nippon Shokakibyo Gakkai Zasshi. 1993. A case of incidence of ulcerative colitis during the therapy of interferon for hepatitis $\mathrm{C}$.

20. Watanabe T, Hirono $\mathrm{H}$, Hasegawa $\mathrm{K}$, et al. Literature review in cases with exacerbation of ulcerative colitis induced by treatment with interferon and/or ribavirin. Journal of gastroenterology and hepatology. 2011; 26:1709-16. [PubMed: 22097938]

21. Salguiero P, Lago P, Pedroto I. Diagnosis of inflammatory bowel disease in chronic hepatitis C patients treated with pegylated interferon and ribavirin: Coincidence or consequence? J Crohns Colitis. 2013; 7:194.

22. Efe C, Roach EC, Purnak T, et al. Chronic hepatitis C, inflammatory bowel disease and interferon therapy. J Crohns Colitis. 2012; 6:626-7. [PubMed: 22398083]

23. Tursi A. Rapid onset of ulcerative colitis after treatment with PEG-interferon plus ribavirin for chronic hepatitis C. Inflammatory Bowel Diseases. 2007; 13:1189-1190. [PubMed: 17427238]

24. Altnbas A, Koybasoglu F, Aktas E, et al. Ulcerative colitis triggered by pegylated interferon alone therapy for chronic hepatitis C. Inflammatory Bowel Diseases. 2011; 17:1050. [PubMed: 20623698]

25. Bongiovanni M, Ranieri R, Ferrero S, et al. Crohn's disease onset in an HIV/hepatitis C virus coinfected woman taking pegylated interferon alpha-2b plus ribavirin. AIDS. 2006; 20:1989-90. [PubMed: 16988527]

26. Khalil A, Lucidarme D, Desurmont P, et al. Crohn's disease associated with interferon and ribavirin treatment for chronic hepatitis C. Gastroenterologie clinique et biologique. 2005; 29:1936. [PubMed: 15795671]

27. Yamamoto Y, Sakatani N, Yano S, et al. Interferon induced IBD-like acute colitis--two cases of patients with chronic active hepatitis. The Japanese journal of gastro-enterology. 1995; 92:1293-6.

28. Watanabe T, Inoue M, Harada K, et al. A case of exacerbation of ulcerative colitis induced by combination therapy with PEG-interferon alpha-2b and ribavirin. Gut. 2006; 55:1682-3. [PubMed: 17047132]

29. Mitoro A, Yoshikawa M, Yamamoto K, et al. Exacerbation of ulcerative colitis during alphainterferon therapy for chronic hepatitis C. Internal Medicine. 1993; 32:327-31. [PubMed: 8102914]

30. Abdelmalek MF, Liu C, Valentine JF. Successful treatment of chronic hepatitis C with pegylated interferon, ribavirin, and infliximab in a patient with Crohn's disease. The American journal of gastroenterology. 2007; 102:1333-4. [PubMed: 17531027]

31. Salcedo-Mora X, Mate J, Medina J, et al. Chronic hepatitis C and Crohn's disease: nosocomial infection treatment with PEG-interferon plus ribavirin. Digestion. 2006; 73:210-4. [PubMed: 16883071]

32. Sawada K, Ohnishi K, Kusaka T, et al. Dramatic response to granulocytapheresis in a Crohn's disease case complicated by hepatitis C virus. Digestive diseases and sciences. 2005; 50:1533-4. [PubMed: 16110849]

33. Sawada K, Ohnishi K, Fukunaga K, et al. A new treatment for HCV-ulcerative colitis comorbidity intolerant to INF-alpha. The American journal of gastroenterology. 2003; 98:228-9. [PubMed: 12526978]

34. Campbell S, Ghosh S. Infliximab therapy for Crohn's disease in the presence of chronic hepatitis C infection. European journal of gastroenterology \& hepatology. 2001; 13:191-2. [PubMed: 11246620]

35. De Diego Lorenzo A, Kashoob M, Romero M, et al. Treatment with recombinant interferon alfa-2b of a patient with chronic hepatitis $\mathrm{C}$ and concomitant ulcerative colitis. Revista espanola de enfermedades digestivas. 1997; 89:399-401. [PubMed: 9280430]

36. Derijks LJ, Gilissen LP, Hooymans PM, et al. Review article: thiopurines in inflammatory bowel disease. Alimentary pharmacology \& therapeutics. 2006; 24:715-29. [PubMed: 16918876] 
37. Gish RG. Treating HCV with ribavirin analogues and ribavirin-like molecules. The Journal of antimicrobial chemotherapy. 2006; 57:8-13. [PubMed: 16293677]

38. Biancone L, Del Vecchio Blanco G, Pallone F, et al. Immunomodulatory drugs in Crohn's disease patients with hepatitis B or C virus infection. Gastroenterology. 2002; 122:593-4. [PubMed: 11845808]

39. Lin A, Thadareddy A, Goldstein MJ, et al. Immune suppression leading to hepatitis C virus reemergence after sustained virological response. Journal of medical virology. 2008; 80:1720-2. [PubMed: 18712814]

40. Magy N, Cribier B, Schmitt C, et al. Effects of corticosteroids on HCV infection. International journal of immunopharmacology. 1999; 21:253-61. [PubMed: 10408633]

41. Klintmalm GB, Davis GL, Teperman L, et al. A randomized, multicenter study comparing steroidfree immunosuppression and standard immunosuppression for liver transplant recipients with chronic hepatitis C. Liver transplantation. 2011; 17:1394-403. [PubMed: 21850690]

42. Stangl JR, Carroll KL, Illichmann M, et al. Effect of antimetabolite immunosuppressants on Flaviviridae, including hepatitis C virus. Transplantation. 2004; 77:562-7. [PubMed: 15084936]

43. Samonakis DN, Germani G, Burroughs AK. Immunosuppression and HCV recurrence after liver transplantation. Journal of hepatology. 2012; 56:973-83. [PubMed: 21963518]

44. Fukuda R, Ishimura N, Ishihara $S$, et al. Intrahepatic expression of pro-inflammatory cytokine mRNAs and interferon efficacy in chronic hepatitis C. Liver. 1996; 16:390-9. [PubMed: 9021719]

45. Zein NN. Etanercept as an adjuvant to interferon and ribavirin in treatment-naive patients with chronic hepatitis $\mathrm{C}$ virus infection: a phase 2 randomized, double-blind, placebo-controlled study. Journal of hepatology. 2005; 42:315-22. [PubMed: 15791697]

46. Peterson JR, Hsu FC, Simkin PA, et al. Effect of tumour necrosis factor alpha antagonists on serum transaminases and viraemia in patients with rheumatoid arthritis and chronic hepatitis $\mathrm{C}$ infection. Annals of the rheumatic diseases. 2003; 62:1078-82. [PubMed: 14583571]

47. Lin M, Blonski W, Buchner A, et al. The Influence of Anti-TNF Therapy on the Course of Chronic Hepatitis C Virus Infection in Patients with Inflammatory Bowel Disease. Digestive diseases and sciences. 2013; 58:1149-56. [PubMed: 23179145]

48. McHutchison J, Lawitz E, Shiffman M, et al. Peginterferon alfa-2b or alfa-2a with ribavirin for treatment of hepatitis C infection. N Engl J Med. 2009; 361:580-93. [PubMed: 19625712] 


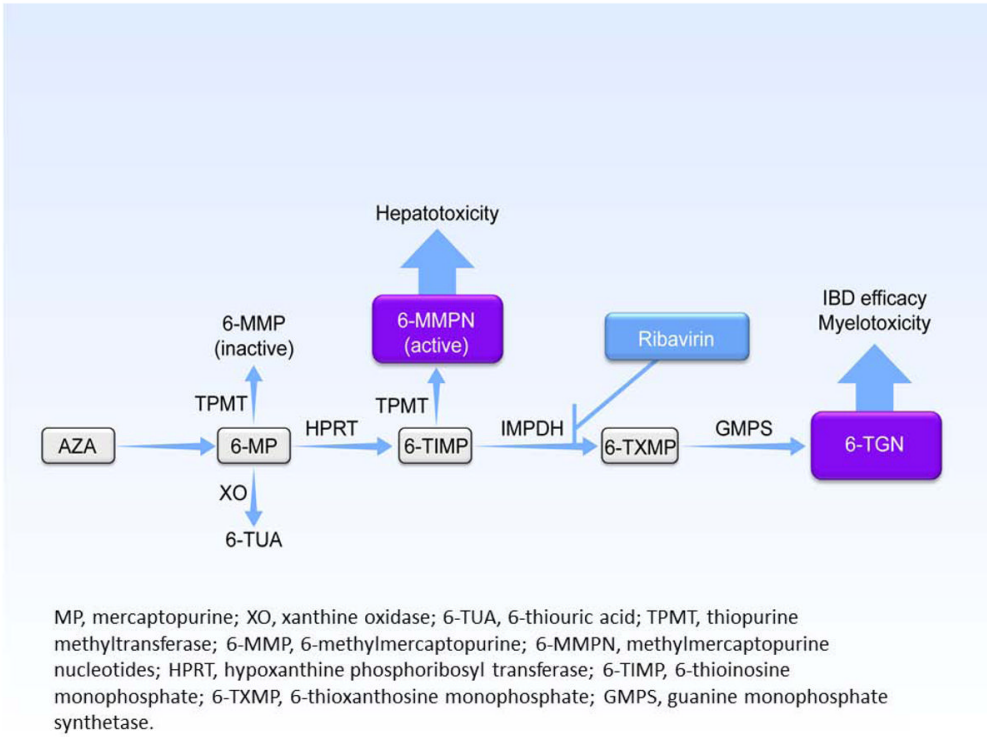

Figure 1.

Metabolism of azathioprine (AZA). Ribavirin blocks inosine monophosphate dehydrogenase (IMPDH), resulting in increased methylated derivatives and decreased 6- thioguanine nucleotide (6-TGN) levels 
Table 1

Baseline bowel disease characteristics of 15 patients with inflammatory bowel disease and hepatitis $\mathrm{C}$ infection at the time at treatment initiation.

\begin{tabular}{|l|c|}
\hline Characteristics & Data \\
\hline Median age, years (range) & $53(30-68)$ \\
\hline Sex (M/F) & $9 / 6$ \\
\hline IBD type & \\
\hline UC & 8 \\
\hline Extensive colitis & 5 \\
\hline Left-sided colitis & 2 \\
\hline Proctitis & - \\
\hline Unknown & 1 \\
\hline CD & 7 \\
\hline Ileitis & 3 \\
\hline Colitis & - \\
\hline Ileocolitis & 3 \\
\hline Unknown & 1 \\
\hline Median IBD duration, years (range) & $15(0-44)$ \\
\hline Baseline IBD activity & \\
\hline Remission & 13 \\
\hline Active & 2 \\
\hline Treatment agents & 7 \\
\hline 5-ASA & - \\
\hline Budesonide & \\
\hline Azathioprine & \\
\hline Anti-TNF & \\
\hline & \\
\hline
\end{tabular}

IBD, inflammatory bowel disease; UC, ulcerative colitis; CD, Crohn's disease; 5-ASA, 5-aminosalicylate; TNF, tumor necrosis factor. 
Table 2

Baseline liver disease characteristics of 15 patients with inflammatory bowel disease and hepatitis $\mathrm{C}$ infection, prior to antiviral therapy initiation.

\begin{tabular}{|l|l|}
\hline Characteristics & Subjects $(\mathbf{n = 1 5})$ \\
\hline Time since HCV diagnosis (median, range) & $3.5(0-17)$ \\
\hline Fibrosis stage & \\
\hline F0 & 3 \\
\hline F1 & - \\
\hline F2 & 2 \\
\hline F3 & 6 \\
\hline F4 & 4 \\
\hline HCV genotype & \\
\hline 1 & 10 \\
\hline 2 & 2 \\
\hline 3 & 3 \\
\hline HCV RNA (IU/mL, median, range) & $3,800,000(18,325-16,000,000)$ \\
\hline ALT (U/I, median) & $78(16-232)$ \\
\hline
\end{tabular}

$\mathrm{HCV}$, hepatitis $\mathrm{C}$ virus; RNA, ribonucleic acid; ALT, alanine transaminase 


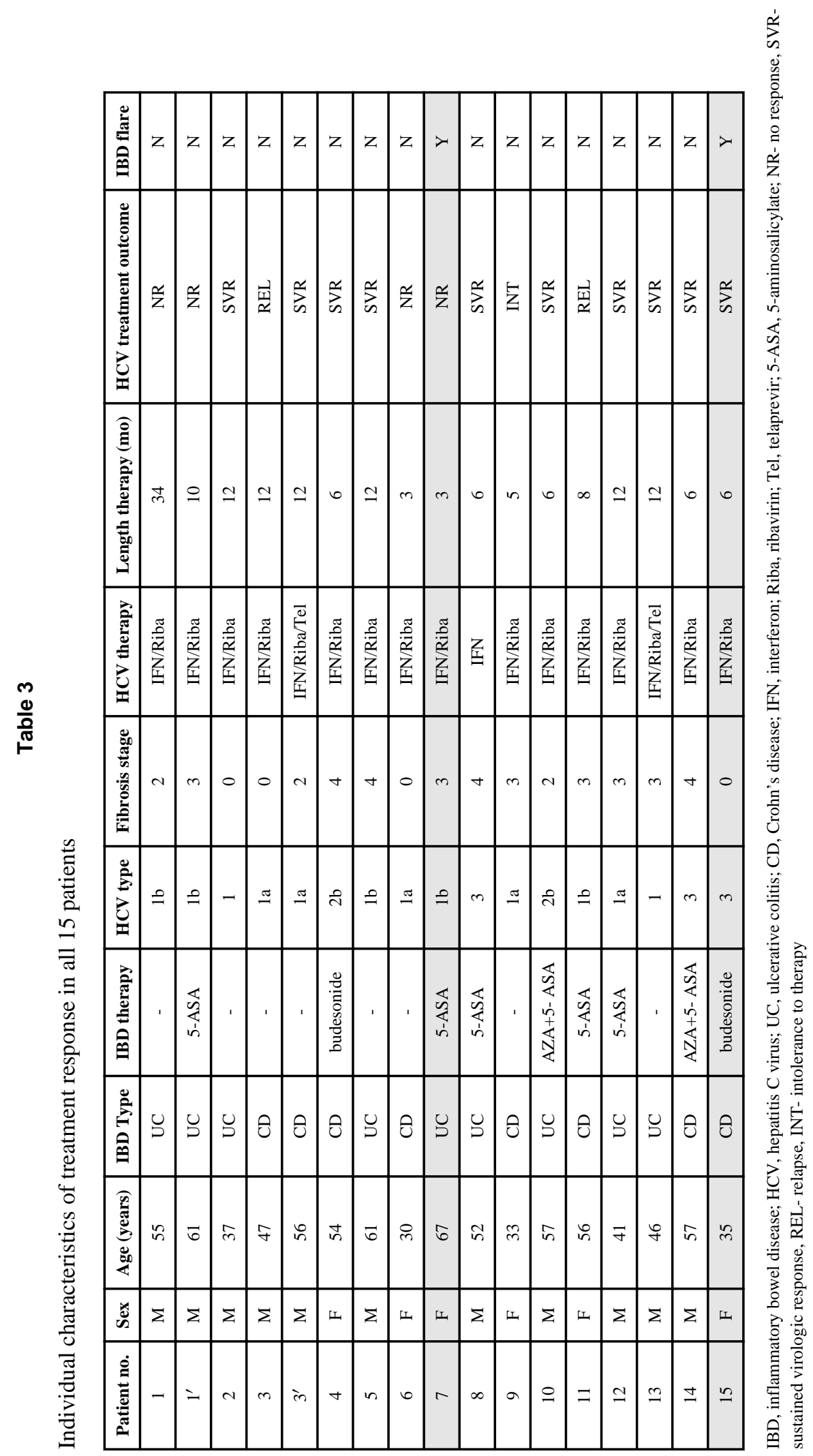


Table 4

Hematological parameters before and during HCV treatment.

\begin{tabular}{|c|c|c|c|}
\hline Parameter & Before (median) & After (median) & Change (median) \\
\hline WBC $\left(\times 10^{9} / \mathrm{L}\right)$ & 6.4 & 2.3 & 4 \\
\hline ANC $\left(\times 10^{9} / \mathrm{L}\right)$ & 3.6 & 1 & 2.7 \\
\hline Hemoglobin $(\mathrm{g} / \mathrm{dL})$ & 14.4 & 10.9 & 3.7 \\
\hline Platelets $\left(\times 10^{9} / \mathrm{L}\right)$ & 201 & 126 & 75 \\
\hline
\end{tabular}

WBC- white blood cells, ANC- absolute neutrophil count 